Original article

\title{
Prevalence of depression and anxiety among mothers of children with neuro-developmental disorders at a tertiary care centre, Puducherry
}

\author{
Nousheen Fatima $^{\mathrm{a}}$, Palanivel Chinnakali ${ }^{\mathrm{b},{ }^{*}}$, Sathish Rajaa ${ }^{\mathrm{b}}$, Vikas Menon ${ }^{\mathrm{c}}$, Nivedita Mondal ${ }^{\mathrm{d}}$, \\ Venkatesh Chandrasekaran ${ }^{\mathrm{e}}$ \\ ${ }^{a}$ MPH Jipmer International School of Public Health, Jawaharlal Institute of Postgraduate Medical Education and Research (JIPMER), Puducherry, 605006, India \\ ${ }^{\mathrm{b}}$ Department of Preventive and Social Medicine, Jawaharlal Institute of Postgraduate Medical Education and Research (JIPMER), Puducherry, 605006, India \\ ${ }^{\mathrm{c}}$ Department of Psychiatry, Jawaharlal Institute of Postgraduate Medical Education and Research (JIPMER), Puducherry, 605006, India \\ ${ }^{\mathrm{d}}$ Department of Neonatology, Jawaharlal Institute of Postgraduate Medical Education and Research (JIPMER), Puducherry, 605006, India \\ ${ }^{\mathrm{e}}$ Department of Paediatrics, Jawaharlal Institute of Postgraduate Medical Education and Research (JIPMER), Puducherry, 605006, India
}

\section{A R T I C L E I N F O}

\section{Keywords:}

Neuro-developmental disorder in children Disability in children

Depression in mother Anxiety in mother

Psychopathology in mother

Socio-economic factors for depression/ anxiety

\begin{abstract}
A B S T R A C T
Background: Parents of children with neuro-developmental disorder (NDD) experience psychiatric disorders like depression and anxiety; and mother being the main care-giver is at a higher risk. Socio-demographic conditions of the families also augment depression.

Objective: To estimate the prevalence of depression and/or anxiety among mothers of children with NDD availing care at a tertiary care centre, Puducherry, India.

Materials and methods: We conducted a cross sectional study from among mothers of children with NDD attending the paediatric clinics between September and October 2019. All mothers were administered PHQ-9 and GAD-7 tools to screen for depression and anxiety, respectively. Those who failed the screens were administered the MINI International Neuropsychiatric Inventory (MINI-PLUS) version 7.0.2 to confirm the diagnosis of depression and anxiety. Prevalence of depression and/or anxiety were presented with $95 \%$ confidence intervals.

Results: A total of 120 mothers were included. Of those, mothers of children with epilepsy were maximum (40\%) followed by Attention Deficit Hyperactivity disorder (27\%), Intellectual Disability (14\%), Cerebral Palsy (12\%) and Autism spectrum disorder (7\%). Of the total, 52 mothers were screened positive for depression and 46 (37.5\%, 95\%CI 29.2-46.4) were diagnosed with depression. As for anxiety, 91 mothers were screened positive and 52 (43.3\%, 95\% CI 34.7-52.3) were diagnosed with anxiety. 36 (30\% 95\% CI 22.3-38.6) mothers had both depression and anxiety.

Conclusion: Depression and anxiety were common among mothers of children with NDD. Hence screening and counseling of these mothers need to be considered.
\end{abstract}

\section{Introduction}

Neuro-development among children is a dynamic inter-relationship between various components which includes brain, genetic, cognitive, emotional and behavioral processes across the lifetime of the child. ${ }^{1}$ The common neuro-developmental disorders (NDD) among children are epilepsy, cerebral palsy, attention deficit hyperactivity disorders, autism spectrum disorders and intellectual disability. Recent studies done in middle income countries and India have showed prevalence of NDD to be nearly $7.5 \%$ and $9 \%$ respectively. ${ }^{1}$

Often the disabled child is in need of support, with respect to physical needs, social needs and emotional well-being, and for this they rely on their family, particularly the mother. Care of a neuro-developmentally disabled child is a huge challenge for the parents and they are always at an increased risk of suffering from other psychopathologies like anxiety and depression. ${ }^{2}$ Studies have shown that the prevalence of depression and anxiety among these mothers to be as high as $68 \%$ and $52 \%$ respectively. Mothers are reported to be more depressed owing to

\footnotetext{
Abbreviations: NDD, Neuro-developmental Disorders; ASD, Autism Spectrum Disorder; ADHD, Attention Deficit Hyperactivity Disorder; INR, Indian National Rupees.

* Corresponding author. Department of Preventive and Social Medicine, JIPMER, Puducherry, India.

E-mail addresses: fatimanousheen61@gmail.com (N. Fatima), palaniccm@gmail.com (P. Chinnakali), psrajaa2410@gmail.com (S. Rajaa), drvmenon@gmail.com (V. Menon), nive.m8@gmail.com (N. Mondal), cvenkatesh@hotmail.com (V. Chandrasekaran).
} 
their need to balance between the needs of the child and household chores, and without any added help, they might feel isolated, over-burdened and dissatisfied with their life. ${ }^{2,3}$

Mothers have also reported of not getting enough sleep, lack of participation in exercises, not having regular, nutritious diet and failing to seek any medical advice for them resulting in: clinical anxiety and depression, isolation from social gatherings, social activities, higher stress and poor quality of life. ${ }^{2-s 4}$ The expected risk of psychopathologies among the mothers of children with cognitive problems can be intensified by the socio-economic condition of the family ${ }^{9}$ (Borst et al., 2010).

Although the overall burden of psychiatric morbidities among these mothers is quite high and associated with poor outcomes in children, policies and practices mainly serve only the children with neurodevelopmental disorder. ${ }^{5}$

In India, there is limited literature focusing on the parental impact of raising children with NDD and their risk of developing various psychopathologies. Hence, it is important to fill this lacuna as well-being of the mother is directly correlated with the well-being of the child and the family. ${ }^{2}$ Therefore, we conducted this study to find the proportion of mothers of children with NDD having depression and or anxiety attending a tertiary care center, Puducherry and its association with the socio-demographic factors and child characteristics.

\section{Materials and methods}

\subsection{Study design, population and setting}

We conducted a facility based cross-sectional analytical study in the out-patient department of a tertiary care center, Puducherry, India from February to December 2019. Patients from Puducherry and neighboring districts of Tamil Nadu and state of Kerala avail services from this centre. The study was conducted among the mothers of children with selected NDD attending follow-up clinics for their children in: the high-risk newborn clinic under the department of neonatology with a daily OPD of 12-15 children as well as in child neurology and child psychiatry weekly clinics under the department of paediatrics with the weekly OPD attendance of 20-25 children. A Psychiatrist was a part of the two above mentioned clinics to treat the mental health problems and conditions of the children. Data was collected in the month of September and October 2019. The selected NDDs included in our study were epilepsy, cerebral palsy, intellectual disability, Attention Deficit Hyperactivity Disorder (ADHD) and Autism Spectrum Disorder (ASD).

\subsection{Sample size}

Assuming the proportion of anxiety and depression among mothers to be $45.9 \%$ and $45.2 \%$ respectively ${ }^{5,6}$; respectively with $20 \%$ relative precision and alpha error of 5\% (95\% confidence level), sample size was calculated to be 114 for depression and 117 for anxiety using OpenEpi version 3.01 software. A sample size of 117 was finalized, however, a total of 120 mothers were interviewed for the study. Consecutive eligible mothers were included.

\subsection{Data variables, sources and data collection}

We captured socio-demographic information of the mothers like age, education, occupation, monthly family income, chronic illness and family history of psychiatric disorders using a semi-structured questionnaire. Information about the characteristics of children like age, gender, type of neuro-developmental disorder and age at diagnosis was obtained from the case records of the child.

Screening of mothers for depression and anxiety was done using Patient Health Questionnaire-9 (PHQ-9) and Generalized Anxiety Disorder-7 (GAD-7) questionnaire, respectively. These questionnaires are validated in Tamil language by CMC Vellore earlier, so the necessary pernmisiions for using the same was sought before start of the study.
Table 1

Socio-demographic characteristics of mothers of children with NDD and their children attending a tertiary care center, Puducherry, $2019(\mathrm{~N}=120)$.

\begin{tabular}{|c|c|c|}
\hline Characteristics & Categories & Number (percentage) \\
\hline \multirow[t]{2}{*}{ Age (years) } & $\geq 30$ & $78(65.0)$ \\
\hline & $<30$ & $42(35.0)$ \\
\hline \multirow[t]{2}{*}{ Education (years) } & $0-10$ & $78(65.0)$ \\
\hline & 11 and above & $42(35.0)$ \\
\hline \multirow[t]{2}{*}{ Marital status } & Married & $114(95.0)$ \\
\hline & Widow & $6(5.0)$ \\
\hline \multirow[t]{2}{*}{ Type of family } & Nuclear & $62(51.7 \%)$ \\
\hline & Joint & $58(48.3 \%)$ \\
\hline \multirow[t]{2}{*}{ Family history of psychiatric disorder } & Yes & $5(4.2)$ \\
\hline & No & $115(95.8)$ \\
\hline \multirow[t]{4}{*}{ Monthly family income (INR) } & $<4000$ & $35(29.2)$ \\
\hline & $4000-4999$ & $31(25.8)$ \\
\hline & $5000-10000$ & $27(22.5)$ \\
\hline & $>10,000$ & $27(22.5)$ \\
\hline \multirow[t]{2}{*}{ Chronic illness in mother ${ }^{a}$} & Yes & $11(9.7)$ \\
\hline & No & $109(90.3)$ \\
\hline \multirow[t]{2}{*}{ Gender of the child } & Male & $82(62.3)$ \\
\hline & Female & $38(31.7)$ \\
\hline \multirow[t]{2}{*}{ Associated co-morbidities in child ${ }^{\mathrm{b}}$} & Yes & $71(59.2)$ \\
\hline & No & $49(40.8)$ \\
\hline \multirow[t]{2}{*}{ Epilepsy } & Yes & $48(40.0)$ \\
\hline & No & $72(60.0)$ \\
\hline \multirow[t]{2}{*}{ ADHD } & Yes & $32(26.7)$ \\
\hline & No & $88(73.3)$ \\
\hline \multirow[t]{2}{*}{ Intellectual disability } & Yes & $17(14.2)$ \\
\hline & No & $103(85.8)$ \\
\hline \multirow[t]{2}{*}{ Cerebral palsy/ASD } & Yes & $23(19.2)$ \\
\hline & No & $97(90.8)$ \\
\hline
\end{tabular}

${ }^{\text {a }}$ Chronic illness: hypertension, diabetes mellitus, hyperthyroidism etc.

b Associated co-morbidities: seizure disorder, speech and learning disorders, auditory impairment etc.

Mothers who scored 10 or more on PHQ-9 were considered as screened positive for depression and similarly those who scored four or more on GAD-7 were considered as screened positive for anxiety and were further evaluated for a lifetime diagnosis of major depression or anxiety using MINI International Neuropsychiatric Inventory (MINI-PLUS) version 7.0.2. The principal investigator was trained for a week in the department of psychiatry for administering the above tools.

\subsection{Ethics approval}

Study protocol was reviewed and approved by Institutional Ethics Committee for observational studies of Jawaharlal Institute of Postgraduate Medical Education and Research, India (JIP/IEC/2019/0313). The purpose of the study was explained to the mothers and informed consent was obtained before the interview. Privacy and confidentiality were ensured. Mothers diagnosed with depression and/or anxiety were referred to the department of psychiatry for further evaluation and necessary treatment was initiated.

\subsection{Statistical analysis}

Data analysis was done using SPSS version 17.0 and data was entered using EpiCollect5 version 1.14; a smart phone based application. Categorical variables were expressed as proportions whereas the continuous variables were expressed as mean (SD) or median (IQR) based on normality.

We summarized depression and anxiety as proportion with $95 \%$ confidence interval (CI). Association of depression and or anxiety with the socio-demographic characteristics was assessed using chi-square test and unadjusted prevalence ratio with $95 \% \mathrm{CI}$ was calculated.

Multivariable regression analysis (log binomial model) was done by taking variables with $\mathrm{p}$-value of $<0.2$ in unadjusted analysis into the 


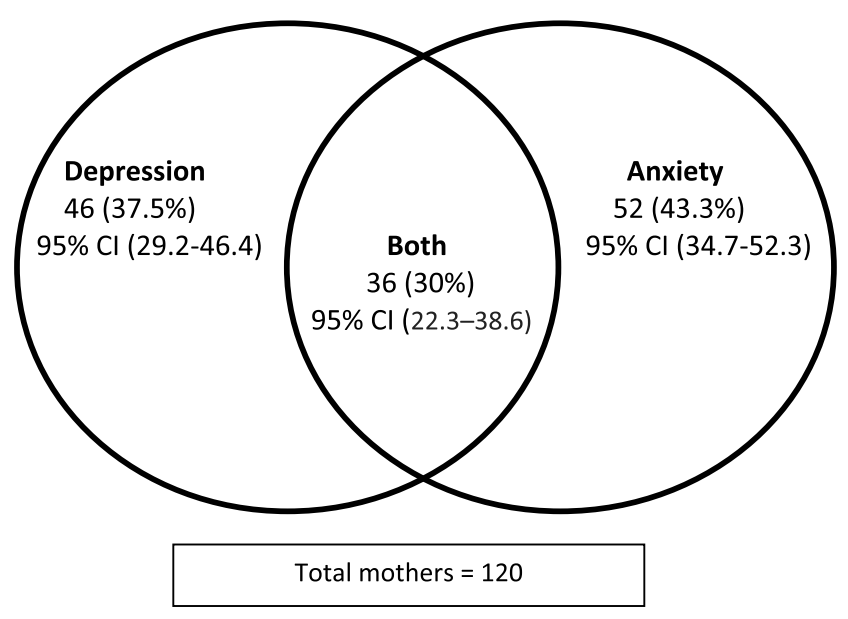

Fig. 1. Proportion of mothers of children with NDD diagnosed with depression, anxiety and both attending a tertiary care center, Puducherry $2019(\mathrm{~N}=120)$.

model, to identify the independent factors associated with the outcomes of the study, adjusted prevalence ratios with $95 \%$ CI were also calculated. A p-value of less than 0.05 was considered statistically significant.

\section{Results}

Of the 120 mothers of children with NDD included; 78 (65\%) belonged to the age group of 30 years and above. Minor difference was noticed in the number of mothers belonging to nuclear $62(51.7 \%)$ and joint families 58 (48.3\%). Five (4.2\%) mothers had a family history of psychiatric disorder and $93(77.5 \%)$ had monthly family income less than 5000 INR (Table 1). Among the children, 82 (62.3) were boys and $38(31.7 \%)$ were females. The mean (SD) age of the children was 6.9 (3.7) years. About $66(55.0 \%)$ of children were more than three years of age. Forty eight (40\%) children had epilepsy, 32 (27\%) had ADHD and
17 (14\%) had intellectual disability. Cerebral palsy was seen in 14 (12\%) children and ASD was found in 9 (8\%) children. Seventy one (59\%) children had associated co-morbidities as well (Table 1 ).

Of total, 53 (44.2\%) mothers were screened positive for depression and $91(75.8 \%)$ were screened positive for anxiety. On further evaluation, 46 (37.5\%, 95\% CI 29.2-46.4) mothers were diagnosed with depression and 52 (43.3\%, 95\% CI 34.7-52.3) mothers were diagnosed with anxiety. Thirty-six (30\% 95\% CI 22.3-38.6) mothers had both depression and anxiety (Fig. 1).

Factors associated with depression are described in Table-2. In adjusted analysis, family history of psychiatric disorder (aPR $1.995 \% \mathrm{CI}$ 1.5-2.5; $\mathrm{p}<0.01$ ) and co-morbidities among children (aPR $2.595 \% \mathrm{CI}$ $1.4-4.4 ; \mathrm{p}<0.01$ ) were associated with depression. Table. 3 shows the factors associated with anxiety. Chronic illness in mother (aPR $1.895 \%$ CI 1.4-2.4; $\mathrm{p}<0.01$ ) and children having attention deficit hyperactivity disorder (aPR 1.7 95\% CI 1.0-2.9; p- 0.04) were associated with anxiety in mother. The following characteristics were associated with a diagnosis of both depression and anxiety (Table-4): family history of psychiatric disorder (aPR 1.9, 95\% CI 1.5-2.5; p- 0.06), male gender of the child (aPR 2.0 95\% CI 1.1-3.7; p-0.02), co-morbidity in children. (aPR 3.4 95\% CI 1.5-7.6; p < 0.01), children with ADHD (aPR 1.8 95\% CI 1.0-3.3; p-0.04), intellectual disability (aPR 2 95\% CI 1.0-3.6; p-004) and autism spectrum disorder (aPR 2.6 95\% CI 1.2-5.8; p-0.01).

\section{Discussion}

Our study sought to assess the burden of depression and anxiety amongst the mothers of children with common NDD attending a public health facility in south India. In our sample, we found high level of burden; $38 \%$ of mothers had depression, $43 \%$ had anxiety and $30 \%$ had both. The mother identified with depression and/or anxiety were informed about their mental health status and were referred to the department of psychiatry for further help. Our estimates were much higher compared to that of National Mental Health Survey 2015-16; the prevalence of depression in women of general population was $2.97 \%$

Table 2

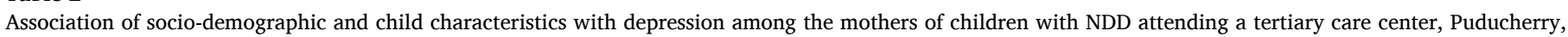
$2019(\mathrm{~N}=120)$.

\begin{tabular}{|c|c|c|c|c|c|c|}
\hline Characteristics & Categories & Total $(\mathrm{N})$ & Depression $\mathrm{n} \%$ & Unadjusted PR (95\%CI) & Adjusted PR (95\%CI) & P value ${ }^{\#}$ \\
\hline Total (N) & & 120 & $46(38.3)$ & & & \\
\hline \multirow[t]{2}{*}{ Age of mother (years) } & $<30$ & 78 & $17(40.5)$ & $1.08(0.68-1.7)$ & - & - \\
\hline & $\geq 30$ & 42 & $29(37.2)$ & 1 & - & - \\
\hline \multirow[t]{2}{*}{ Marital status } & Married & 114 & $44(38.6)$ & $1.1(0.36-3.6)$ & - & - \\
\hline & Widow & 6 & $3(33.3)$ & 1 & - & - \\
\hline \multirow[t]{2}{*}{ Family history of psychiatric disorder } & Yes & 5 & $4(80.0)$ & $2.1(1.32-3.61)$ & $2.08(1.5-2.7)$ & $<0.001$ \\
\hline & No & 115 & $42(36.5)$ & 1 & 1 & - \\
\hline \multirow[t]{4}{*}{ Monthly family income (INR) } & $<4000$ & 35 & $17(48.6)$ & $1.8(0.91-3.86)$ & - & - \\
\hline & $4000-4999$ & 31 & $10(32.3)$ & $1.2(0.54-2.81)$ & - & - \\
\hline & $5000-10000$ & 27 & $12(44.4)$ & $1.7(0.79-3.69)$ & - & - \\
\hline & $>10,000$ & 27 & $7(26.0)$ & 1 & - & - \\
\hline \multirow[t]{2}{*}{ Chronic illness in mother* } & Yes & 11 & $4(36.3)$ & 1 & - & - \\
\hline & No & 109 & $42(38.5)$ & $1.0(0.46-2.39)$ & - & - \\
\hline \multirow[t]{2}{*}{ Gender of the child } & Male & 82 & 35 (42.7) & $1.4(0.84-2.57)$ & $1.53(0.89-2.63)$ & 0.11 \\
\hline & Female & 38 & $11(29.0)$ & 1 & 1 & - \\
\hline \multirow[t]{2}{*}{ Associated co-morbidities in child** } & Yes & 71 & $36(50.7)$ & $2.4(1.36-4.52)$ & $2.25(1.2-4.2)$ & 0.01 \\
\hline & No & 49 & $10(20.4)$ & 1 & 1 & - \\
\hline \multirow[t]{2}{*}{ History of Epilepsy in child } & Yes & 48 & $14(29.2)$ & $0.65(0.39-1.09)$ & $0.99(0.61-1.62)$ & 0.99 \\
\hline & No & 72 & $32(44.4)$ & 1 & & \\
\hline \multirow{2}{*}{ History of ADHD in child } & Yes & 32 & 15 (46.9) & $1.33(0.83-2.11)$ & - & - \\
\hline & No & 88 & $31(35.2)$ & 1 & & \\
\hline \multirow[t]{2}{*}{ History of Intellectual disability in child } & Yes & 17 & $9(52.9)$ & $1.47(0.87-2.47)$ & $1.21(1.1-2.34)$ & $<0.001$ \\
\hline & No & 103 & $37(35.9)$ & 1 & & \\
\hline \multirow[t]{2}{*}{ History of Cerebral palsy/ASD in child } & Yes & 23 & $8(34.7)$ & $0.88(0.48-1.63)$ & - & - \\
\hline & No & 97 & $38(39.1)$ & 1 & & \\
\hline
\end{tabular}

Adjusted analysis included family history of psychiatric disorder, gender of the child and associated co-morbidities in the child.

*Chronic illness: hypertension, diabetes mellitus, hyperthyroidism etc.

**Associated co-morbidities: seizure disorder, speech and learning disorders, auditory impairment etc.

\#P-value of adjusted analysis. 
Table 3

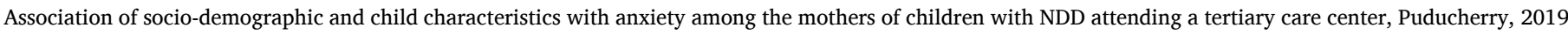
$(\mathrm{N}=120)$.

\begin{tabular}{|c|c|c|c|c|c|c|}
\hline Characteristics & Categories & Total (N) & Anxiety (n \%) & Unadjusted PR (95\%CI) & Adjusted PR (95\%CI) & P value ${ }^{\#}$ \\
\hline Total $(\mathrm{N})$ & & 120 & $52(43.3)$ & & - & - \\
\hline \multirow[t]{2}{*}{ Age of mother (years) } & $<30$ & 78 & $19(45.2)$ & $1.1(0.70-1.63)$ & - & - \\
\hline & $\geq 30$ & 42 & $33(42.3)$ & 1 & - & - \\
\hline \multirow[t]{2}{*}{ Marital status } & Married & 114 & $4(66.7)$ & $1.6(0.86-2.90)$ & - & - \\
\hline & Widow & 6 & $48(42.1)$ & 1 & - & - \\
\hline \multirow[t]{2}{*}{ Family history of psychiatric disorder } & Yes & 5 & $3(60.0)$ & $1.4(0.66-2.98)$ & - & - \\
\hline & No & 115 & $49(42.6)$ & 1 & - & - \\
\hline \multirow[t]{4}{*}{ Monthly family income (INR) } & $<4000$ & 35 & $18(51.4)$ & $1.2(0.72-2.20)$ & - & - \\
\hline & 4000-4999 & 31 & $9(29.0)$ & $0.7(0.35-1.45)$ & - & - \\
\hline & $5000-10000$ & 27 & $14(51.8)$ & $1.2(0.71-2.27)$ & - & - \\
\hline & $>10,000$ & 27 & $11(40.7)$ & 1 & - & - \\
\hline \multirow[t]{2}{*}{ Chronic illness in mother* } & Yes & 11 & $7(63.6)$ & $1.5(0.94-2.54)$ & $1.75(1.3-2.3)$ & 0.00 \\
\hline & No & 109 & $45(41.3)$ & 1 & 1 & - \\
\hline \multirow[t]{2}{*}{ Gender of the child } & Male & 82 & $37(45.1)$ & $1.1(0.72-1.81)$ & - & - \\
\hline & Female & 38 & $15(39.5)$ & 1 & - & - \\
\hline \multirow[t]{2}{*}{ Associated co-morbidities in child ${ }^{* *}$} & Yes & 71 & $38(53.5)$ & $1.9(1.14-3.06)$ & $1.4(0.8-2.4)$ & 0.13 \\
\hline & No & 49 & $14(28.6)$ & 1 & 1 & - \\
\hline \multirow{2}{*}{ History of Epilepsy in child } & Yes & 48 & $15(31.2)$ & $0.60(0.37-0.97)$ & $0.78(0.42-1.46)$ & 0.45 \\
\hline & No & 72 & $37(51.4)$ & 1 & 1 & \\
\hline \multirow[t]{2}{*}{ History of ADHD in child } & Yes & 32 & $18(56.2)$ & $1.45(0.97-2.17)$ & $1.31(0.83-2.07)$ & 0.23 \\
\hline & No & 88 & $34(38.6)$ & 1 & 1 & \\
\hline \multirow[t]{2}{*}{ History of Intellectual disability in child } & Yes & 17 & $10(58.8)$ & $1.44(0.90-2.28)$ & $1.07(.61-1.86)$ & 0.80 \\
\hline & No & 103 & $42(40.7)$ & 1 & 1 & \\
\hline \multirow[t]{2}{*}{ History of Cerebral palsy/ASD in child } & Yes & 23 & $9(39.1)$ & $0.88(0.50-1.53)$ & - & - \\
\hline & No & 97 & $43(44.3)$ & 1 & & \\
\hline
\end{tabular}

NDD - Neuro-developmental disorder, INR- Indian National Rupees, ASD-autism spectrum disorder, ADHD-attention deficit hyperactivity disorder.

Adjusted analysis included chronic illness in mother, associated co-morbidities in the child and NDD in child.

*Chronic illness: hypertension, diabetes mellitus, hyperthyroidism etc.

**Associated co-morbidities: seizure disorder, speech and learning disorders, auditory impairment etc.

\#P-value of adjusted analysis.

Table 4

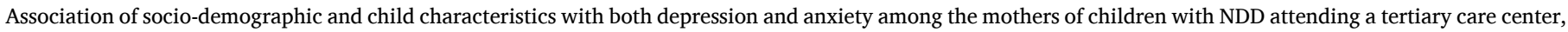
Puducherry, $2019(\mathrm{~N}=120)$.

\begin{tabular}{|c|c|c|c|c|c|c|}
\hline Characteristics & Categories & Total $(\mathrm{N})$ & Both depression and anxiety $\mathrm{n} \%$ & Unadjusted PR (95\%CI) & Adjusted PR (95\%CI) & $\mathrm{P}_{\text {value }}^{\#}$ \\
\hline Total (N) & & 120 & $36(30.0)$ & & - & - \\
\hline \multirow[t]{2}{*}{ Age of mother (years) } & $<30$ & 78 & $14(33.3)$ & $1.2(0.67-2.06)$ & - & - \\
\hline & $\geq 30$ & 42 & $22(28.2)$ & 1 & - & - \\
\hline \multirow[t]{2}{*}{ Marital status } & Married & 114 & $2(33.3)$ & $1.1(0.34-3.59)$ & - & - \\
\hline & Widow & 6 & $34(29.8)$ & 1 & - & - \\
\hline \multirow[t]{2}{*}{ Family history of psychiatric disorder } & Yes & 5 & $3(60.0)$ & $2.0(0.96-4.52)$ & $1.7(1.0-2.6)$ & 0.01 \\
\hline & No & 115 & $33(28.7)$ & 1 & 1 & - \\
\hline \multirow{4}{*}{ Monthly family income (INR) } & $<4000$ & 35 & $12(34.3)$ & $1.8(0.74-4.62)$ & $0.3(0.2-0.7)$ & 0.003 \\
\hline & $4000-4999$ & 31 & $7(22.6)$ & $1.2(0.44-3.40)$ & $0.6(0.4-0.9)$ & 0.03 \\
\hline & $5000-10000$ & 27 & $12(44.4)$ & $2.4(0.98-5.89)$ & $0.4(0.2-1.02)$ & 0.058 \\
\hline & $>10,000$ & 27 & $5(18.5)$ & 1 & 1 & - \\
\hline \multirow[t]{2}{*}{ Chronic illness in mother* } & Yes & 11 & $4(36.4)$ & $1.2(0.54-2.85)$ & - & - \\
\hline & No & 109 & $32(29.4)$ & 1 & - & - \\
\hline \multirow{2}{*}{ Gender of the child } & Male & 82 & $28(34.1)$ & $1.6(0.82-3.21)$ & $2.1(1.1-3.7)$ & 0.02 \\
\hline & Female & 38 & $8(21.0)$ & 1 & 1 & - \\
\hline \multirow[t]{2}{*}{ Associated co-morbidities in child** } & Yes & 71 & $30(42.2)$ & $3.4(1.55-7.65)$ & $3.0(1.3-6.8)$ & 0.008 \\
\hline & No & 49 & $6(12.2)$ & 1 & 1 & - \\
\hline \multirow{2}{*}{ History of Epilepsy in child } & Yes & 48 & $8(16.6)$ & $0.42(0.21-0.85)$ & $0.55(0.29-1.02)$ & 0.06 \\
\hline & No & 72 & $28(38.8)$ & 1 & 1 & \\
\hline \multirow[t]{2}{*}{ History of ADHD in child } & Yes & 32 & $15(46.9)$ & $1.96(1.16-3.31)$ & $1.02(0.87-1.1)$ & 0.79 \\
\hline & No & 88 & $21(23.8)$ & 1 & 1 & \\
\hline \multirow[t]{2}{*}{ History of Intellectual disability in child } & Yes & 17 & $7(41.1)$ & $1.46(0.76-2.79)$ & - & - \\
\hline & No & 103 & $29(28.1)$ & 1 & & \\
\hline \multirow[t]{2}{*}{ History of Cerebral palsy/ASD in child } & Yes & 23 & $6(26.1)$ & $0.84(0.39-1.78)$ & - & - \\
\hline & No & 97 & $30(30.9)$ & 1 & & \\
\hline
\end{tabular}

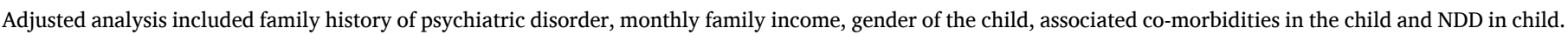
*Chronic illness: hypertension, diabetes mellitus, hyperthyroidism etc.

**Associated co-morbidities: seizure disorder, speech and learning disorders, auditory impairment etc.

\#P-value of adjusted analysis.

and that of generalized anxiety was found $0.8 \%{ }^{10}$ (Gururaj et al., 2018). Our results are similar to a study from Tamil Nadu, India among mothers of children with cerebral palsy. A study among mothers of children with
NDD from Gujarat, India reported higher prevalence estimate of anxiety of $57 \%$ and this could be due to higher prevalence of family history of psychiatric disorders. Of all the NDDs, anxiety was found to be more 
common in mothers of children having attention deficit hyperactivity disorder. ${ }^{7}$

Family history of psychiatric disorders is a well-known risk factor and we found this was associated with depression in mothers. ${ }^{7}$ Family history may have been under reported due to stigma. About three fifths of the children had co-morbidities and their mothers had significantly higher prevalence of depression. Higher the number of morbidities in child and severity of the NDDs, mothers face challenges in caring the child that may affect the emotional wellbeing leading to depression. These sub-group of mothers of children with multiple morbidities need to be identified before development of psychological morbidity.

Strengths of our study include two step assessment using validated tools by a single trained investigator for screening and diagnosis of depression and anxiety. We included children with NDD from various clinics thus broadening the spectrum of NDD. One major limitation of our study was the lack of a comparison group, however nationally representative estimates were available for comparison with general population. Generalizability of the findings is limited since the estimates were based on sample from a limited geographical region.

Literature have supported to rope in support of mothers of children with NDD to improve their mental and psychological well-being. Social work methods such as intervention techniques, counseling and group therapies can be used among the mothers of children with NDD to overcome depression and anxiety ${ }^{11}$ (Sumesh et al., 2019). As early as the child gets diagnosed with NDD, mother needs to be sensitized about the psychiatric morbidities which she can develop later. Routine periodic screening for psychiatric morbidities during the follow up visits of the child can be implemented. Counseling and coping strategies can be provided to these mothers through supervised peer mentors. Non-specialist like medical officers and ANM can be trained to address the mental health needs of these mothers at the primary care level. ${ }^{8}$ Involvement of other family members in the standard treatment plan of the children needs to be emphasized as this adds support to the mother.

To conclude, mothers of children with NDDs have higher level of depression and anxiety compared to estimates from general population. This calls for focus on mental health needs of mothers of children with NDD and justifies the need to promote the well-being of these mothers for improving their as well as their family's quality of life.

\section{Ethics approval}

Approved by Human Institute Ethics Committee JIPMER (JIP/IEC/
2019/0313).

\section{Source of funding}

None.

\section{Declaration of competing interest}

None.

\section{Acknowledgement}

We are immensely grateful to all the staff posted in these clinics for their encouragement and support throughout the course of this study.

\section{References}

1 Arora NK, Nair MK, Gulati S, et al. Neurodevelopmental disorders in children aged 2-9 years: population-based burden estimates across five regions in India. PLoS Med. 2018;15(7). e1002615.

2 Ben Thabet J, Sallemi R, Hasiri I, et al. Psycho-emotional impact of a child's disability on parents. Arch Pediatr Organe Off Soc Francaise Pediatr. 2013;20(1):9-16.

3 Chandravanshi G, Sharma KK, Jilowa CS, et al. Prevalence of depression in mothers of intellectually disabled children: a cross-sectional study. Med J DY Patil Vidyapeeth. 2017;10(2):156-161.

4 Sapkota N, Pandey AK, Deo BK, Shrivastava MK. Anxiety, depression and quality of life in mothers of intellectually disabled children. J Psychiatr Assoc Nepal. 2017;6(2): 28-35.

5 Toulgui E, Jemni S, Samia F, et al. Depression and anxiety in mothers of children with cerebral palsy: comparative study. Ann Phys Rehabil Med. 2016;59:e9.

6 Al-Farsi OA, Al-Farsi YM, Al-Sharbati MM, Al-Adawi S. Stress, anxiety, and depression among parents of children with autism spectrum disorder in Oman: a case-control study. Neuropsychiatric Dis Treat. 2016;12:1943.

7 Dave D, Mittal S, Tiwari D, et al. Study of anxiety and depression in caregivers of intellectually disabled children. J Res Med Dent Sci. 2014;2(1):8-13.

8 Dykens EM, Fisher MH, Taylor JL, Lambert W, Miodrag N. Reducing distress in mothers of children with autism and other disabilities: a randomized trial. Pediatrics. 2014;134(2):e454-e463.

9 Borst JB. Caregivers of seriously disabled children and their relationship issues with the labor market pop. Res Policy Rev. 2014;24:467-488.

10 Gururaj G, Varghese M, Benegal V, et al. NMHS collaborators group. In: National Mental Health Survey of India. vol. 128. NIMHANS Publ; 2016.

11 Sumesh K, Jeryda JO, Eljo G. A study on depression experienced by the parents of children with cerebral palsy. Cauvery Res J. 2009;2(2):107-114. 